\title{
The Behavior of Concrete Cylinders Confined by JFRP Composites: Effect of $\mathrm{KOH}$ Solution
}

\author{
Yasmina Ed-Dariy ${ }^{1}$, Nouzha Lamdouar ${ }^{1}$,Toufik Cherradi ${ }^{1}$, Ancuta Rotaru ${ }^{2}$, Marinela Barbuta ${ }^{2}$, Petru \\ Mihai $^{2}$, Loredana Judele ${ }^{2}$ \\ ${ }^{1}$ Mohammadia School of Engineers, Mohammed V University of Rabat, \\ Ibn Sina Avenue, Rabat, Morocco \\ yasminaeddariy@research.emi.ac.ma ; nlamdouar@gmail.com ; tcherradi@gmail.com ; \\ ${ }^{2}$ Faculty of Civil Engineering and Building Services, Gheorg Assachi Technical University of Iasi , \\ Bulevardul Profesor Dimitrie Mangeron 67,700050, Iași, Romania \\ arotaru502@yahoo.com,barbuta31bmc@yahoo.com,petru.mihai@tuiasi.ro,ljudele@yahoo.co.uk
}

\begin{abstract}
The objective of this experimental study is to evaluate the effect of treated and untreated Jute fibers on the behavior of concrete members. Fifteen samples of concrete reinforced by JFRP are subjected to a compression test. The main issues investigated are the ultimate load, and the effect of treatment on fiber morphology. It has shown that the treatment of fibers by $2 \%$ of Potassium hydroxide during $24 \mathrm{~h}$ in a liquor ratio of 10:1 decreases the maximum load capacity. On the other hand, the reinforcement of concrete members using untreated Jute Fibers Reinforced Polymer (JFRP) increases the maximum load capacity. As well as the augmentation of the number of layers of fibers fabric increases the maximum load capacity of concrete of 36.6\% and 57.3\% in the case of C3-JFRP-2L, C3-JFRP-3L respectively.
\end{abstract}

Keywords: Jute-FRP composites, epoxy resin, reinforcement, alkaline treatment, adhesion, concrete.

\section{Introduction}

In the field of Civil Engineering, composites have been used as structural strengthening systems for different reinforced concrete (RC) elements such as columns, beams, beam-column joints, and walls[1]-[8]. However, the majority of such applications are based on composites with non-degradable synthetic fibers such as E-glass, carbon and aramid[6], [9], [10]. It was mentioned in recent years that the natural's fibers could be an interesting alternative to glass fibers because of their lightness and low environmental impact [11], [12]. It was noted that the stiffness and the maximum loads of concrete beams increase with the reinforcement by natural fibers plates [13]. It was found also that the reinforcement of beams using the Jute fiber-reinforced polymer fabrics, offers an augmentation in load capacity of $62.5 \%$ [14], [15]. While the cellulose fibers are incompatible with the hydrophobic polymers, which leads to less interfacial adhesion between the fiber and the matrix. However, the quality of the fiber-matrix interface is important for the use of natural fibers as reinforcing fibers for polymers[16], [17]. It's therefore very often necessary to modify the surface of the fibers to optimize this interface by using the physical or chemical methods[18]. These modification methods are of different efficiency for the adhesion between matrix and fiber, and can increase the quality of the interface as it can decrease the resistance of the fibers. It was concluded that the excessive treatment of natural fibers using $\mathrm{NaOH}$ or $\mathrm{KOH}$ could have a negative effect on the properties of the fibers[19] [20] [21]. It was also stated that the chemically treated composites showed a relatively greater decrease in the tensile strength, which proves that the treated composites undergo greater degradation compared to the untreated composites[21].

This study shows the mechanical behavior of cylinders concrete reinforced by composite materials based on untreated and in the case of Jute fibers treated in 2\% of Potassium hydroxide for 24 hours in a liquor ratio of 10: 1were subjected to the compression test. The first section presents the materials used and the methodology followed. The second section resumes the results obtained from the compression test in terms of Maximum Load capacity. The effect of treatment on the morphology is presented in the third section. 


\section{Methodology}

\subsection{Treatment of Jute fibers by Potassium hydroxide}

The natural fibers are impregnated in $2 \%$ of $\mathrm{KOH}$ solution, during 24 hours, under the following climatic conditions: $18^{\circ} \mathrm{C}$ and $88 \%$ relative humidity. The fibers are washed in distilled water whose $\mathrm{PH}$ reaches 7 , so as to remove the residues of the $\mathrm{KOH}$ solution. Then, they are dried for 6 hours at a $100^{\circ} \mathrm{C}$.

\subsection{Preparation of samples}

The Jute fibers fabric was cut to the dimensions mentioned in ASTM D $3039(25 * 250 \mathrm{~mm})$ [22], in order to characterize the mechanical properties of the composite. Table.1 resume the properties of the Sikadur ${ }^{\mathrm{TM}} 330$ epoxy resin used for the application of Jute fiber fabrics on concrete. All samples are cured at room conditions during 7 days.

Table 1: Properties of sikadur 330.

\begin{tabular}{cccccc}
\hline Resin & $\begin{array}{c}\text { Density } \\
\mathbf{k g . d m} \\
\text { mixed }\end{array}$ & $\begin{array}{c}\text { Compressive } \\
\text { strength } \\
\mathbf{f}_{\mathbf{c}, \mathbf{a}}[\mathbf{M P a}]\end{array}$ & $\begin{array}{c}\text { Tensile } \\
\text { strength } \\
\mathbf{f}_{\mathbf{t}, \mathbf{a}}[\mathbf{M P a}]\end{array}$ & $\begin{array}{c}\text { Module of } \\
\text { elasticity } \\
\mathbf{E}_{\mathbf{a}}[\mathbf{G P a}]\end{array}$ & $\begin{array}{c}\text { Elongation at } \\
\text { break, } \boldsymbol{\varepsilon}_{\mathbf{u}}[\%]\end{array}$ \\
\hline Sika-dur 330 & 1.3 & $\begin{array}{c}30(7 \\
\left.\text { days }+23^{\circ} \mathrm{C}\right)\end{array}$ & $\begin{array}{c}33.8(7 \text { days }+ \\
\left.23^{\circ} \mathrm{C}\right)\end{array}$ & $\begin{array}{c}4.5 \\
\left(7 \text { days }+23^{\circ} \mathrm{C}\right)\end{array}$ & 0.9 \\
\hline
\end{tabular}

\section{Testing}

\subsection{Tensile Test}

The Jute fibers laminates are subjected to the tensile test using the Universal testing machine WAW-600 E, with a displacement speed of $2 \mathrm{~mm} / \mathrm{min}$. All laminates have displayed failure modes that are in accordance with ASTM D 3039 (Paragraph 11.9). The mechanical properties obtained are summarized in Table. 2.

Table 2: Properties of the JFRP laminate.

\begin{tabular}{lc}
\cline { 2 - 2 } & Mechanical properties \\
\hline Ultimate tensile strength [MPa] & 45.2 \\
\hline Elasticity modulus at failure [GP] & 4.26 \\
\hline Elongation at failure [\%] & 1.06 \\
\hline
\end{tabular}

\subsection{Compression Test}

The fifteen samples of Jute Fiber Reinforced Polymer reinforced concrete members are subjected to compression testing in the laboratory of Composite Materials, of the Faculty of Civil Engineering and Building Services, Gheorghe Asachi University, Iasi, Romania. The capacity of this machine is $600 \mathrm{KN}$ and the loading speed applied is $4 \mathrm{KN} / \mathrm{s}$. The results are obtained using the data acquisition system Maxtest software. Table. 3 group the code abbreviations using for the specimens that were reinforced by the JFRP with and without treatment.

Table 3: Code abbreviations.

\begin{tabular}{ll}
\hline Code & Signification \\
\hline JFRP & Jute Fibers Reinforced Polymer \\
\hline KOH & Potassium hydroxide \\
\hline C3-R & Plain concrete cylinder \\
\hline C3-JFRP-2L & Concrete reinforced by 2 Layers of Jute-FRP \\
\hline
\end{tabular}




\begin{tabular}{ll}
\hline C3-JFRP-3L & Concrete reinforced by 3 Layers of Jute-FRP \\
\hline C3-JFRP-KOH-2L & Concrete reinforced 2 Layers of treated Jute-FRP \\
\hline C3-JFRP-KOH-3L & Concrete reinforced by 3 Layers of treated Jute-FRP \\
\hline
\end{tabular}

\section{Results}

\subsection{Maximum Load capacity}

As shown in Fig. 1 and Fig. 2, the strengthening of concrete members with Jute fibers fabric reinforced polymer increases the maximum load capacity. The value of the high load capacity was noted in the case of specimens reinforced by 3 layers of fiber (C3-JFRP-3L) followed by specimens reinforced by 2L (C3-JFRP-2L) with an increase of $97 \mathrm{KN}$ and $62.6 \mathrm{KN}$ respectively, compared to unreinforced specimens. On the other hand, the specimens reinforced with treated fibers showed a decrease of 9.8 KN and 6.2 KN in the case of C3-JFRP-KOH-2L and C3-JFRP-KOH-3L severally, compared to reinforced specimens (Fig.1 and Fig.2).

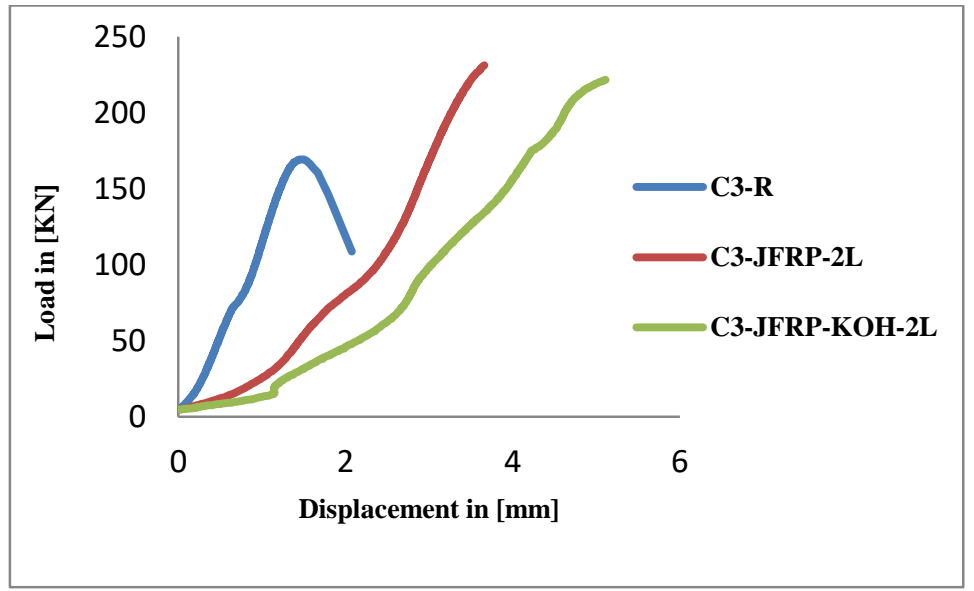

Fig .1: Load-displacement curves of unreinforced column and reinforced column by $2 \mathrm{~L}$ of treated and untreated Jute fibers.

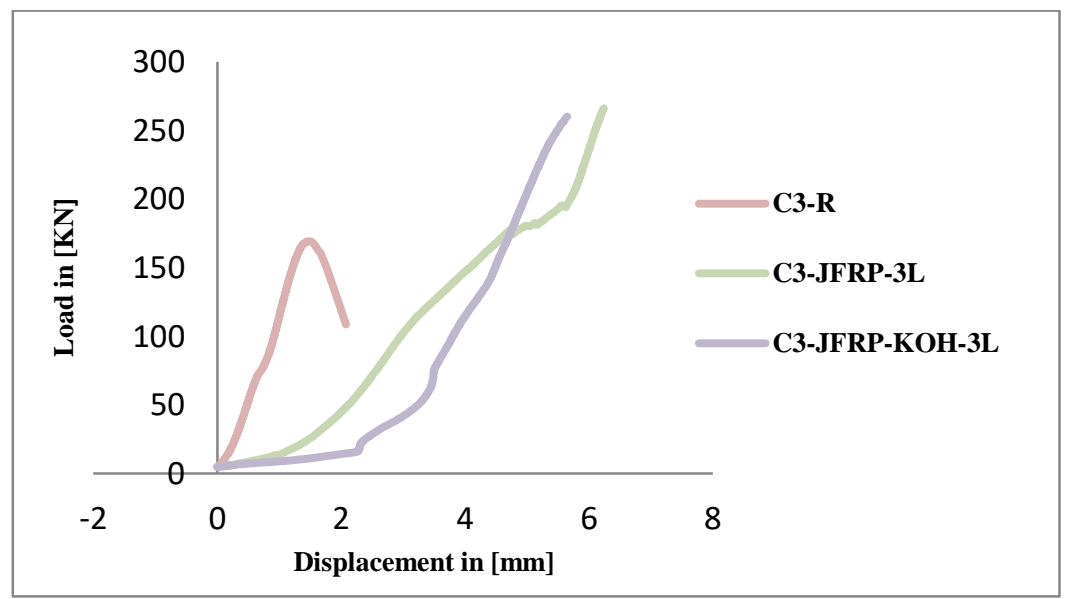

Fig .2: Load-displacement curves of unreinforced columns and reinforced columns by $3 \mathrm{~L}$ of treated and untreated Jute fibers. 


\subsection{Effect of Treatment on Fiber Morphology}

Porous support means a larger contact area, which has the effect of increasing the breaking energy necessary for the separation of the assembled materials. According to the fiber morphology surface obtained by scanning electron microscopy and as shown in Fig.3, the fibers are more cleanly and with a smooth surface in the case of treated fibers (Fig.3(b)) compared the untreated fibers (Fig.3.(a )). The figure 3(b) doesn't illustrate the presence of holes which means that detachment of the primary wall , more specifically, the lignin and hemicellulose have not been remote it by the $2 \%$ of $\mathrm{KOH}$ solution.

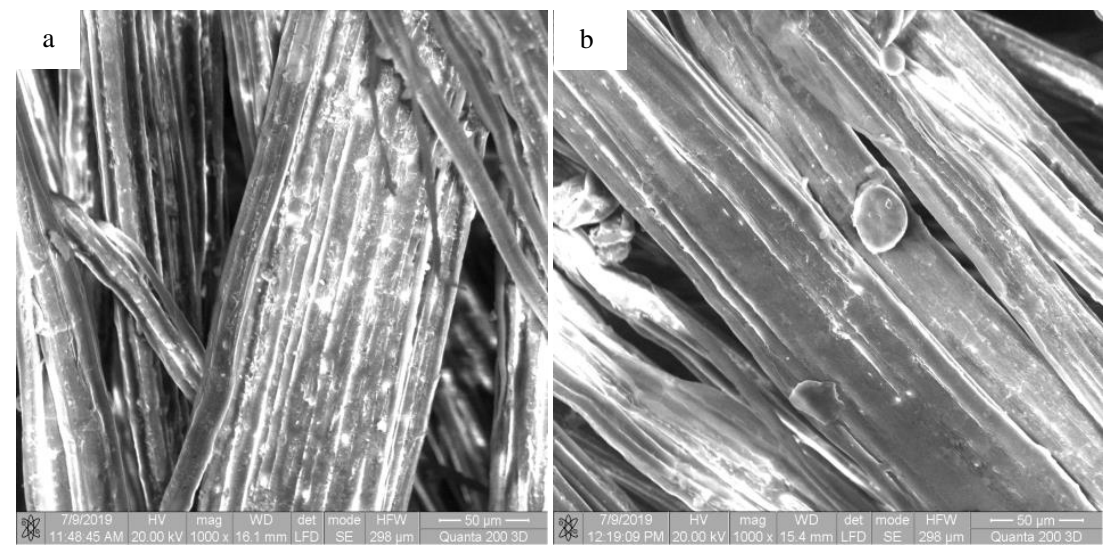

Fig. 3: Jute fibers observed on a microscopic scale longitudinal view (a) Jute fiber without treatment (b) Jute fibers treated with $2 \% \mathrm{KOH}$

\section{Conclusions}

It could be concluded from this study that:

1) The excessive treatment of Jute fibers using $2 \%$ of Potassium hydroxide $(\mathrm{KOH})$ during $24 \mathrm{~h}$ in a liquor ratio of 10:1 has a negative effect on the properties of fibers which lead to a decrease of the maximum load capacity of concrete reinforced by Jute-FRP composites.

2) The reinforcement of concrete members with Jute fibers reinforced polymer has shown an increase of the maximum load capacity.

3) The increasing number of layers increased the maximum load capacity of concrete of $36.6 \%$ and $57.3 \%$ in the case of C3-JFRP-2L, C3-JFRP-3L respectively.

\section{Acknowledgements}

We would like to acknowledge the great support of Sika Company and we would like to show our gratitude to the all the persons how worked with us in this paper, specially, Mr. MARINESCU and Mr. POENARU of the Faculty of civil engineering and building services, Gheorg Assachi Technical University of Iasi, Romania.

\section{References}

[1] A. K. Al-Tamimi, R. A. Hawileh, J. A. Abdalla, H. A. Rasheed, R. Al-Mahaidi, « Durability of the bond between CFRP plates and concrete exposed to harsh environments », J. Mater. Civ. Eng., vol. 27, n 9, p. 04014252, 2015.

[2] A. Mirmiran et M. Shahawy, « Behavior of concrete columns confined by fiber composites », J. Struct. Eng., vol. 123, $\mathrm{n}^{\circ}$ 5, p. 583-590, 1997.

[3] A. S. D. Salama, R. A. Hawileh, J. A. Abdalla, « Performance of externally strengthened RC beams with side-bonded CFRP sheets », Compos. Struct., vol. 212, p. 281-290, 2019. 
[4] M. Z. Naser, R. A. Hawileh, J. A. Abdalla, « Fiber-reinforced polymer composites in strengthening reinforced concrete structures: A critical review », Eng. Struct., vol. 198, p. 109542, 2019.

[5] A. Hadhood, M. H. Agamy, M. M. Abdelsalam, H. M. Mohamed, T. A. El-Sayed, « Shear strengthening of hybrid externally-bonded mechanically-fastened concrete beams using short CFRP strips: Experiments and theoretical evaluation », Eng. Struct., vol. 201, p. 109795, 2019.

[6] R. A. Hawileh, W. Nawaz, J. A. Abdalla, E. I. Saqan, «Effect of flexural CFRP sheets on shear resistance of reinforced concrete beams », Compos. Struct., vol. 122, p. 468-476, 2015.

[7] S. Mousa, H. M. Mohamed, B. Benmokrane, « Strength and deformability aspects of circular concrete members reinforced with hybrid carbon-FRP and glass-FRP under flexure », J. Compos. Constr., vol. 23, nº 2, p. 04019005, 2019.

[8] R. A. Hawileh, M. Z. Naser, J. A. Abdalla, «Finite element simulation of reinforced concrete beams externally strengthened with short-length CFRP plates », Compos. Part B Eng., vol. 45, n 1, p. 1722-1730, 2013.

[9] R. A. Hawileh, H. A. Rasheed, J. A. Abdalla, A. K. Al-Tamimi, « Behavior of reinforced concrete beams strengthened with externally bonded hybrid fiber reinforced polymer systems », Mater. Des., vol. 53, p. 972-982, 2014.

[10]N. Al Nuaimi, M. G. Sohail, R. A. Hawileh, J. A. Abdalla, K. Douier, « Durability of Reinforced Concrete Beams Strengthened by Galvanized Steel Mesh-Epoxy Systems under Harsh Environmental Conditions », Compos. Struct., p. $112547,2020$.

[11]P. C. Georgel, « Résines époxydes renforcées avec des fibres naturelles », Université Laval, 2009.

[12]G. Silva, S. Kim, R. Aguilar, J. Nakamatsu, « Natural fibers as reinforcement additives for geopolymers-A review of potential eco-friendly applications to the construction industry », Sustain. Mater. Technol., vol. 23, p. e00132, 2020.

[13]I. Cervantes, L. AungYong, K. Chan, Y.-F. Ko, S. Mendez, « Flexural retrofitting of reinforced concrete structures using Green Natural Fiber Reinforced Polymer plates », in ICSI 2014: Creating Infrastructure for a Sustainable World, 2014, p. 1051-1062.

[14]M. J. John, S. Thomas, « Biofibres and biocomposites », Carbohydr. Polym., vol. 71, n 3, p. 343-364, févr. 2008, doi: 10.1016/j.carbpol.2007.05.040.

[15]Chen, C., Yang, Y., Yu, J., Yu, J., Tan, H., Sui, L., Zhou, Y., « Eco-friendly and mechanically reliable alternative to synthetic FRP in externally bonded strengthening of RC beams: Natural FRP », Compos. Struct., vol. 241, p. 112081, 2020.

[16]K. Sever, M. Sarikanat, Y. Seki, G. Erkan, Ü. H. Erdoğan, S. Erden, « Surface treatments of jute fabric: The influence of surface characteristics on jute fabrics and mechanical properties of jute/polyester composites », Ind. Crops Prod., vol. $35, n^{\circ} 1$, p. 22-30, 2012.

[17] H. Burrola-Núñez, P. J. Herrera-Franco, D. E. Rodríguez-Félix, H. Soto-Valdez, T. J. Madera-Santana, « Surface modification and performance of jute fibers as reinforcement on polymer matrix: An overview », J. Nat. Fibers, vol. 16, $\mathrm{n}^{\mathrm{0}}$ 7, p. 944-960, 2019.

[18] D. P. Ferreira, J. Cruz, R. Fangueiro, «Surface modification of natural fibers in polymer composites », in Green composites for automotive applications, Elsevier, 2019, p. 3-41.

[19] Y. Ed-Dariy, N. Lamdour, T. Cherradi, A. Rotaru, M. Barbuta, P. Mihai, « Effect of alkali treatment of Jute fibers on the compressive strength of normal-strength concrete members strengthened with JFRP composites », J. Appl. Sci. Eng., vol. $23, n^{\circ} 4$, p. $677-685,2020$.

[20] Z. N. Azwa, B. F. Yousif, « Characteristics of kenaf fibre/epoxy composites subjected to thermal degradation », Polym. Degrad. Stab., vol. 98, nº 12, p. 2752-2759, déc. 2013, doi: 10.1016/j.polymdegradstab.2013.10.008.

[21] Y. Ed-Dariy, N. Lamdour, T. Cherradi, A. Rotaru, M. Barbuta, P. Mihai, L. JUDELE. « Experimental investigation of the effects of $\mathrm{NaOH}$ and $\mathrm{KOH}$ solution on the behavior of concrete square columns reinforced by JFRP Composites », 5th World Congress on Civil, Structural, and Environmental Engineering, Lisbon, Portugal, Oct. 18-20, 2020

[22] D. ASTM, « Standard test method for tensile properties of polymer matrix composite materials », 2008. 